\title{
Questes
}

Revue pluridisciplinaire d'études médiévales

\section{Bruits d'enfer. Présence et fonction de l'élément acoustique dans les évocations infernales des textes médiévaux}

Mattia Cavagna

\section{OpenEdition}

Journals

Édition électronique

URL : http://journals.openedition.org/questes/2311

DOI : 10.4000/questes.2311

ISSN : 2109-9472

Éditeur

Les Amis de Questes

\section{Édition imprimée}

Date de publication : 15 mars 2003

Pagination : 4-5

ISSN : 2102-7188

\section{Référence électronique}

Mattia Cavagna, «Bruits d'enfer. Présence et fonction de l'élément acoustique dans les évocations infernales des textes médiévaux », Questes [En ligne], 3 | 2003, mis en ligne le 01 janvier 2014, consulté le 19 septembre 2020. URL : http://journals.openedition.org/questes/2311 ; DOI : https://doi.org/ 10.4000 /questes.2311 


\title{
LES BRUITS DE LA VILLE
}

\author{
Compte-rendu du Séminaire des doctorants médiévistes en Sorbonne
}

décembre et janvier 2002-2003

Centre Raspail, Bibliothèque des Médiévistes, Paris.

\section{Bruits d'enfer. Présence et fonction de l'élément acoustique dans les évocations infernales des textes médiévaux}

\author{
Mattia CAVAGNA
}

Les descriptions de l'au-delà présentées par les textes visionnaires se réfèrent continuellement à des images tirées du monde terrestre : si le paradis est représenté comme un jardin fleuri, rempli des chœurs mélodieux des saints, l'enfer ressemble à un milieu urbain foisonnant d'activités. Les diables sont assimilés à des forgerons ou à des cuisiniers; l'enfer retentit du bruit de leurs instruments de torture (marteaux, enclumes, casseroles), de leurs imprécations et surtout des lamentations des damnés. L'élément acoustique contribue d'une façon décisive à la formation de l'imaginaire infernal. Si, d'un côté, l'enfer apparaît comme un espace discontinu, comme une série de différentes images juxtaposées, de l'autre, les cris des damnés, retentissant partout, donnent une perception spatiale unitaire. Voici deux exemples tirés de la Vision de Tondale :

[les âmes] estoient contraintes de crier si grans cris et si haults qu'on les pooit oyr de toutes les parties d'infer.

Dans une autre version du même texte, on lit :

[les âmes] emploient tout enfer par leurs ullemens et par leur brerie [...] si que toute celle noise venoit au ciel. 
«L'abîme inférieur », la partie la plus profonde de l'enfer, est déterminée par le chaos irréversible, par l'absence de tout ordre, de toute lumière et de tout discernement. Le visionnaire ne peut rien y apercevoir avec sa vue mais peut bien entendre les cris terrifiants qu'en sortent. Dans la Vision de Drithelm, relatée par Bède le Vénérable, ce bruit confus (sonum promiscuum) est comparé aux « rires de la populace ignorante » qui donne libre cours à sa rage contre des prisonniers :

... simul ac cachinnum crepitantem quasi vulgi indocti captis hostibus insultantis.

À côté des récits des visionnaires, on retrouve aussi des évocations infernales dans la littérature hagiographique, romanesque et théâtrale. Dans ce cas, l'élément acoustique joue un rôle encore plus important : les cris des damnés et des démons sont la manifestation directe de l'horreur infernale qui parvient à la surface terrestre.

Dans le Voyage de saint Brendan, l'enfer est représenté comme une île peuplée de forgerons noirs. De leurs forges se dégagent sans cesse des cris terrifiants. Dans le Lancelot en prose, au-dessous du château de la Douloureuse Garde, se cache un fossé qui évoque le puits infernal. De ce puits sortent «si grant noises et si grant criz que tout le pilers an trembloit». Dans la Queste del saint Graal, le bruit d'enfer constitue en soi-même l'objet d'une épreuve : il s'agit d'une tombe d'où sort une voix si horrible qui fait perdre la raison à ceux qui l'entendent.

Le Mystère d'Adam propose une scène infernale réalisée à partir du vacarme provoqué par les démons. La didascalie en donne des indications détaillées :

[diaboli] magnum tripudium inter se facient [...] et vociferabuntur inter se in inferno gaudentes, et collident caldaria et lebetes suos, ut exterius audiantur.

Provoqué par les instruments de torture, par les cris des damnés ou des démons, le bruit terrifiant représente un élément essentiel et omniprésent dans la constitution de l'imaginaire infernal.

(Les citations de la Vision de Tondale sont tirées de deux versions inédites du $\mathrm{XV}^{\mathrm{e}}$ siècle ( ms. Arsenal 3622 ; ms BN fr. 314). L'édition de ces versions du texte fait l'objet de notre Thèse de Doctorat.) 